\title{
Justiça Restaurativa e Crimes Culposos de TRÂNSITO
}

\author{
André Ribeiro Giamberardino* \\ Mário Edson Passerino Fischer da Silva**
}

1 Introdução. 2 Desenvolvimento. 2.1 A proposta do modelo restaurativo de justiça. 2.2 Cidadania e justiça restaurativa. 2.3 Justiça restaurativa nos crimes culposos de trânsito. 3 Conclusão. Referências.

\section{RESUMO}

O paradigma restaurativo é proposto como meio de empoderar o indivíduo e emancipá-lo do estado de apatia no que tange à sua relação com os conflitos e a sua resolução. Com foco específico na área dos crimes culposos de trânsito, a pesquisa foi dividida em duas fases, conjugando metodologia qualitativa baseada em entrevistas não estruturadas e revisão bibliográfica. Para tanto, procedeu-se a pesquisa de consulta processual no âmbito da Segunda Vara de Delitos de Trânsito de Curitiba/PR e na interação com familiares de vítimas de delitos de trânsito e infratores que cumpriam pena restritiva de direitos no Instituto Paz no Trânsito. Sendo o rito restaurativo uma experiência voluntária que incita o diálogo, a reflexão sobre as causas da questão e a formulação conjunta de uma solução para o conflito, ele pode demonstrar que o cidadão é capaz de agir de forma responsável e atuar como um agente modificador da própria realidade sem a presença necessária da tutela punitiva estatal. Tem-se, por fim, que o campo dos crimes culposos e de trânsito se mostra como muito permeável para testar-se a eficácia de tal modelo de justiça, devido à ausência de propósito direto na causação do dano, bem como diante da manifesta ineficácia da pena estatal em sentido preventivo.

Palavras-chave: Justiça Restaurativa. Crimes culposos. Cidadania.

* É Professor de Criminologia e Direito Penal e Defensor Público no Estado do Paraná. Em Curitiba/PR, é Professor na Universidade Federal do Paraná e da Universidade Positivo, na qual é pesquisador do CPJUS - Centro de Pesquisa Jurídica e Social. Compõe o corpo docente, como professor convidado, do Master em "Criminologia critica e sicurezza sociale. Devianza, istituzioni e interazioni psicosociali", da Università di Padova (UniPd) e Università di Bologna (UniBo), Itália. Doutor em Direito do Estado pelo Programa de Pós-graduação em Direito da Universidade Federal do Paraná (2014). Possui Mestrado em Direito pela UFPR e em Criminologia pela Università degli Studi di Padova, e Especialização em Direito Penal e Criminologia pelo Instituto de Criminologia e Política Criminal/ICPC \& UFPR (2008).E-mail: <andre.rg@terra.com.br>.

** Acadêmico de direito do quinto ano da Universidade Federal do Paraná, Facilitador em Práticas Circulares Restaurativas capacitado pelo Tribunal de Justiça do Paraná e estudante bolsista da Alma Mater Studiorum Università di Bologna durante o segundo semestre do ano acadêmico de 2014. E-mail: <mario_fischer94@ hotmail.com>. 


\section{INTRODUÇÃO}

Qual seria o modo mais prudente de se implementar um modelo restaurativo de justiça adequado à seara do direito penal brasileiro e de que forma este poderia contribuir para a mudança da concepção comum acerca da tratativa de conflitos e do exercício da cidadania?

A pesquisa foi dividida em uma etapa teórica e outra essencialmente empírica, utilizando métodos qualitativos de análise. Na primeira, apresentou-se uma compatibilidade de pressupostos entre a abordagem restaurativa, a tratativa penal dos crimes culposos e as peculiaridades inerentes e eventuais destes. $\mathrm{O}$ objetivo primário fora demonstrar que os processos que envolvem a ocorrência de crimes culposos, desde que haja suficiente esclarecimento e consistência probatória em relação aos fatos narrados, criam ambientes propícios ao êxito da aplicação de medidas restaurativas para o encaminhamento de sua resolução. Para tanto, recorreu-se à bibliografia nacional e internacional referentes às reflexões sobre justiça restaurativa e aspectos tanto processuais quanto concernentes à teoria do delito.

$\mathrm{Na}$ segunda etapa, o objetivo fora problematizar a adoção da perspectiva restaurativa diante da possibilidade desta servir como um mecanismo para o desenvolvimento de um autêntico senso de cidadania e responsabilidade - distinto do sentimento de vingança - por parte dos envolvidos ou afetados pelo fato delituoso relacionado, especificamente, aqui, aos crimes culposos de trânsito. A metodologia adotada baseou-se: i) na consulta processual de autos referentes a casos já julgados no âmbito da Segunda Vara de Delitos de Trânsito de Curitiba; ${ }^{1}$ ii) na interação com a equipe psicopedagógica do Instituto Paz no Trânsito (IPTRAN) e com os sentenciados que lá cumpriam penas restritivas de direitos, ${ }^{2}$ incluindo entrevistas não estruturadas, e iii) na reflexão sobre os modos como a abordagem restaurativa poderia contribuir para a construção dialógica da responsabilidade entre os envolvidos no conflito.

\section{DESENVOLVIMENTO}

\subsection{A PROPOSTA DO MODELO RESTAURATIVO DE JUSTIÇA}

No artigo "Geography in court: expertise in adversarial settings", William A. V. Clark argumenta que as cortes possuiriam seus próprios desenhos geográficos e que estes seriam baseados em um modelo de "campo de batalha", no qual dois especialistas se combateriam argumentativamente a fim de demonstrarem a correspondência de seus respectivos pontos de vista em relação à lei. ${ }^{3}$ Segundo tal visão, os papéis principais no processo seriam ocupados pelos especialistas (advogados ou profissionais chamados pela corte a fim de comprovarem determinada tese), e, no fim, o debate deixaria de lado o conflito entre pessoas, não almejando mais a descoberta da "verdade dos fatos" ou a produção da sanção mais adequada. $\mathrm{O}$ objetivo do processo, portanto, seria selecionar qual dos pontos de vista contrapostos seria o mais convincente de ser adotado aos olhos do juiz. 
Malcolm Feeley, por sua vez, em "The Process is the Punishment", complementa a referida abordagem ao delinear que o próprio desenrolar do processo já renderia consequências danosas à vítima e ao réu, seja na vida familiar, no trabalho, seja no nível dos relacionamentos pessoais em geral. ${ }^{4}$ Para o autor, a figura mais influente e notória do rito processual seria o juiz, o qual, geograficamente falando, se encontraria não apenas fisicamente acima dos demais (por se sentar em um local mais alto ou evidente), como também abstratamente (devido ao fato de este reter para si todo o poder decisório). Aos envolvidos no conflito, entretanto, reserva-se um papel totalmente passivo, de modo que esses apenas figurariam como espectadores de uma luta verbal cujo conteúdo tende a ser inacessível a eles, na medida em que é codificado por uma linguagem excessivamente formal e técnica.

A perspectiva restaurativa pretende, justamente, resgatar a participação ativa e empoderada dos sujeitos do conflito como componente imprescindível de qualquer tentativa legítima de sua resolução.

De acordo com Federico Reggio, que tratou dos princípios e das formas de aplicação das práticas restaurativas, inexistiria na atualidade um conceito universal acerca do que é a justiça restaurativa e quais seriam os seus objetivos. Citam-se, então, algumas propostas da presente vertente, como tornar a experiência da vítima um objeto de narração, apresentar a justiça restaurativa como uma antítese à antropologia individualista e ainda fazê-la operar como prova de que o Estado não é necessariamente o único garantidor da ordem jurídica e social. ${ }^{5}$

Fato é que as várias perspectivas dos autores não tornam claros todos os pressupostos da perspectiva restaurativa, mesmo que seja possível identificar elementos essenciais. ${ }^{6}$ Dentre tais elementos, pode-se fazer alusão à questão do empoderamento dos envolvidos no conflito a partir do reconhecimento de que seu espaço/papel no rito processual deve ser relevante, bem como que estes devem ser tratados como seres humanos e não objetos de intervenção. Reggio apontou que, por mais que a ausência de clareza conceitual complique a compreensão da temática, um consenso teórico poderia representar algo ainda mais negativo, pois engessaria o debate de questões as quais talvez necessitem de maiores reflexões. ${ }^{7}$ A proposta do autor em relação a tal problemática foi a de focar-se no conteúdo dos conceitos mais condizentes com a justiça restaurativa, devendo-se identificar o que se tornou uma "visão aceita" e o que é, de fato, uma "visão aceitável” desse paradigma. Dever-se-ia, nessa linha, refletir sobre questionamentos cuja resolução possa definir mais claramente o que se pretende com tal proposta e se esta se apresentaria como uma alternativa ao sistema penal (principalmente no sentido de possuir valores diversos), se o substituiria ou se se manteria paralelo a ele. ${ }^{8}$

Christie, por sua vez, tratou do sequestro institucional do conflito em face de seus próprios sujeitos e das respectivas consequências. Com a formação do Estado Moderno e a burocratização, veio também a profissionalização do trato oficial do "intolerável”, por meio de um aparato institucional oficialmente reconhecido como o único legítimo a tutelar a re- 
solução conflitual e, por fim, a consolidação de um paradigma o qual definiu ser o Estado (na forma do ordenamento jurídico) o "ofendido" universal dos conflitos socialmente relevantes. ${ }^{9}$ Mesmo porque tal aparato jamais objetivou a efetiva "resolução" dos conflitos humanos, aos sujeitos envolvidos em controvérsias, foi delegada uma posição secundária no processo penal. Tais indivíduos passaram a figurar como meras testemunhas dos fatos, perdendo a oportunidade de refletir sobre a função da norma que incidiria sobre seu caso, de trabalhar traumas, de promover a responsabilização do ofensor, no caso da vítima, e de se retratar ou mesmo propor uma forma de compensação, no caso do ofensor. ${ }^{10}$

Howard Zehr, por sua vez, apresentou a justiça restaurativa como uma perspectiva oposta à ótica retributiva, ${ }_{11}^{11}$ pois esta representaria a lógica do sistema e do processo penal. Sua concepção teria como escopo principal o empoderamento das "partes de fato" mediante a conferência do protagonismo processual a estas. Essas partes então dialogariam entre si, com a presença de suas respectivas famílias (quando for o caso) e da comunidade afetada pelo conflito e, sob observação de um mediador, formulariam uma solução em conjunto para a questão. Segundo o autor, tal solução deveria implicar reparação ou compensação, ainda que simbólica, do dano causado. ${ }^{12}$

Nessa senda, certos doutrinadores como Tony Marshall, Paul McCold e Ted Wachtel descrevam a justiça restaurativa como um processo no qual vítima e ofensor se reúnem e, em conjunto, buscam uma solução para o conflito baseando-se no diálogo, ${ }^{13}$ tratando apenas da via operacional da questão, ou seja, das práticas restaurativas. A justiça restaurativa corresponderia, então, a um paradigma, noção defendida por Zehr, ${ }^{14}$ que compreende uma metodologia de resolução conflitual, ainda que alguns de seus aspectos possam ser observados em abordagens procedimentais atreladas a outras perspectivas. A figura da conciliação, por exemplo, é autorizada pela Lei 9.099/1995 no âmbito dos juizados especiais criminais e poderia, em tese, corresponder a uma prática restaurativa: todavia, não seria razoável afirmar que nesses órgãos é adotada a perspectiva restaurativa de forma plena, mesmo porque a abrangência é restrita e a vítima volta a ser "substituída" no instituto da transação penal.

De todo modo, parece certo de que se trata de uma forma mais humana de conduzir o processo e de responder ao crime. Afinal, a atenção do rito restaurativo recai sobre as pessoas, não sobre a punição e a análise dos fatos sob a ótica meramente legal. Reggio, contudo, afirmou que o processo e a justiça restaurativa não são necessariamente opostos, mas possuem premissas diversas, sendo a segunda mais atenta às necessidades concretas das partes de fato, mais inclusiva e calcada na participação dos envolvidos que são incentivados a dialogarem entre si. $^{15} \mathrm{O}$ autor, partidário da vertente maximalista quanto à abrangência do adjetivo "restaurativo", defende a ideia de que as práticas restaurativas deveriam sempre resultar em uma forma de reparação à vítima ou aos familiares desta, mesmo que em nível simbólico, pois o mero "encontro entre ofendido e ofensor", objeto principal da vertente minimalista (encounter theory), não bastaria para por remédio à ofensa e reproduziria a atua- 
ção do Sistema Penal. ${ }^{16}$

A justiça restaurativa teria o objetivo de encorajar a "prestação de contas" do ofensor com a vítima e/ou os familiares desta, oferecendo aos envolvidos um espaço mais propício ao desenvolvimento de empatia e à restauração de vínculos, fazendo que os participantes se reconheçam como cidadãos dignos de respeito e que, devido ao diálogo, as consequências e causas minuciosas da ofensa sejam reveladas.

Carolyn Hoyle, apesar de defender que a justiça restaurativa seria mais adequada quando utilizada para a resolução de crimes de menor potencial ofensivo, reconhece sua potencialidade em casos mais graves, embora apregoe que, para os referidos crimes, tal metodologia deva ser aplicada como funcionalmente complementar ao sistema criminal. Ou seja, segundo a autora, nos citados casos, deve existir uma pena, e a abordagem restaurativa seria aplicada junto à retributiva, afinal o modelo restaurativo não configuraria uma alternativa à punição, mas uma punição alternativa (essencialmente reparativa).${ }^{17}$ Afirmou também que a responsabilização gerada pelo rito restaurativo exitoso atingiria não apenas ao ofensor, ao receptor da censura, mas também: i) ao ofendido, o qual, sendo o receptáculo da reparação, atuaria como agente de controle do cumprimento do acordo restaurativo; ii) à comunidade (quando há), que deveria auxiliar na reintegração do ofensor e iii) às famílias do ofensor e da vítima (quando presentes) as quais ofereceriam suporte emocional aos envolvidos no conflito e os ajudariam com problemas pessoais, por vezes, não relacionados diretamente com a ofensa. Nessa linha, a implementação desse modelo poderia corresponder a uma distribuição da responsabilidade de controle criminal, dividindo essa tarefa entre comunidade e Estado e criando não uma nova forma de governo, mas uma nova forma de governar: ${ }^{18}$ com a intervenção institucional se distanciando materialmente, mas se reproduzindo por meio da comunidade.

Oferece-se aos envolvidos um papel ativo em um espaço de resolução conflitual, no qual, como Nils Christie almejava, seria possível discutir não apenas acerca da função das normas jurídicas relevantes ao caso, mas igualmente fornecer aos agentes participantes (ofendido, ofensor, comunidade, famílias, mediadores e mesmo aos juízes) a chance de refletirem sobre os problemas sócio-estruturais que se relacionam ao fato delituoso. Nesses termos, os envolvidos têm a possibilidade de pensar criticamente em uma solução viável para o conflito de modo proativo e racional, restaurando, então, os vínculos rompidos pela ofensa.

\subsection{CIDADANIA E JUSTIÇA RESTAURATIVA}

Segundo Catherine de Vitto e Philip Oxhorn, em países onde a sociedade civil é "fraca”, a cidadania é refletida em direitos cuja amplitude espelha as assimetrias da estrutura social, garantindo-se o direito de reivindicação e participação política aos grupos sociais que já os possuem e mantendo-se a exclusão dos segregados. ${ }^{19}$ A justiça restaurativa, como 
expressão de um sistema de "micro-justiça" (não coincidente com o portentoso aparato estatal), possibilitaria o desenvolvimento de um outro tipo de relação entre cidadão e Estado, sem, entretanto, recair nas armadilhas inerentes à hipervalorização de cada um destes, como o fez o neoliberalismo ou o paternalismo estatal. Essa atuação conjunta acarretaria o maior engajamento dos cidadãos na resolução de problemas enfrentados pela justiça estatal e, consequentemente, a sua maior inclusão nas estruturas jurídica e política nacionais, visto que estes influenciariam a promoção da "justiça" e fortaleceriam, de tal modo, a democracia. ${ }^{20}$

Tal questão dialoga com os apontamentos de Luiza Maria de Carvalho. A autora criticou o fato de que, na sociedade brasileira, o voto é a máxima expressão da participação popular e adendou que a justiça restaurativa poderia ampliar o exercício democrático, uma vez que permitiria aos cidadãos atuarem ativamente na resolução dos próprios conflitos e ainda como "embaixadores sociais". Com tal termo visou-se a designar os indivíduos que auxiliariam o Estado a identificar possíveis implementações de políticas públicas, cujo êxito poderia não apenas contribuir para sanar a controvérsia concreta entre os envolvidos no conflito, mas igualmente conduzir a solução de problemas sociais mais amplos. ${ }^{21} \mathrm{~A}$ justiça restaurativa, portanto, além de depender do provimento de serviços públicos e atendimentos multidisciplinares para cumprir com sua missão emancipadora, operaria como vetor de orientação de políticas públicas por vezes necessárias à resolução de questões prévias que implicariam a prática de condutas geradoras de conflitos.

As anteriores propostas de atuação conjunta entre Estado e sociedade civil poderiam, então, promover a autêntica cidadania? Afinal, como se concebe a cidadania no contexto da realidade social brasileira? Sobre tais questões refletiu o antropólogo James Holston, o qual afirmou que historicamente a cidadania no Brasil seria caracterizada por ser formalmente inclusiva, mas substancialmente excludente. Nessa linha, embora o status de cidadão tenda a ser legalmente conferido sem muitos pré-requisitos, o usufruto dos direitos reconhecidos aos cidadãos é, na realidade, muito díspar, e a legislação opera de modo a reproduzir e engessar tal distribuição desigual, conferindo privilégios e deveres diversos a diferentes categorias que, entretanto, são compostas por pessoas de status cívico formalmente equivalente. ${ }^{22} \mathrm{O}$ mesmo autor, no artigo Cities and Citizenship, apontou que a cidadania seria a identidade que compreende e coordena todas as demais, correspondendo à superação de status e privilégios que seriam cedidos a uma jurisdição ou nação a partir da celebração de uma espécie de contrato social baseado na igualdade de direitos individuais. Fez-se, então, uma diferenciação entre cidadania formal e substancial. A primeira se baseia nos direitos que o indivíduo possui para ser reconhecido como membro de uma determinada sociedade/nação, porém muitos desses implicam ônus como o serviço militar, e, no caso brasileiro, o de votar. A segunda se refere aos direitos políticos, socioeconômicos, culturais e religiosos que um indivíduo possui e exerce. $\mathrm{O}$ autor concluiu que, embora, em teoria, o reconhecimento da segunda implique a concretização da primeira, na prática, 
o que consistiria a cidadania seria independente do reconhecimento formal por parte do direito positivo. ${ }^{23}$

Boaventura de Sousa Santos refletiu sobre a cidadania em uma perspectiva sociológica, abordando a sua relação com a lógica sistêmica capitalista e com o projeto da modernidade. $\mathrm{O}$ autor apresentou o conceito como uma falsa ideia de representação, sendo a cidadania expressa somente no momento do voto. A lógica capitalista liberal, portanto, marginalizou o princípio da comunidade preconizado por Rousseau, pois inexistiria uma participação ativa, direta, autônoma (no sentido de autêntica) e solidária por parte dos governados na tomada de decisões políticas. ${ }^{24}$ Ao consistir em direitos e deveres, a cidadania enriqueceria a subjetividade dos indivíduos e lhes abriria novos horizontes de autorrealização, mas, em sua pretensão de ser universal, ela reduziu a individualidade nos limites de seus pressupostos, acarretando a previsão de uma série de direitos gerais e abstratos aos destinatários de poder. Ela, então, limitou a atuação estatal, mas, ao mesmo tempo, facilitou o exercício do controle social ao passo que equalizou e universalizou as particularidades dos sujeitos destinatários de poder. ${ }^{25}$

Por sua vez, Teresa Caldeira analisou alguns paradoxos envolvendo o conceito agora debatido. De um lado, a autora demonstrou otimismo com relação ao extenso rol de garantias e direitos previstos na Constituição de 1988 e como isso possibilitou o desenvolvimento de vários movimentos sociais e da democracia. Do outro, adendou que a cidadania não é criação da referida carta e que, apesar dos avanços no campo do direito, a realidade material denuncia que o brasileiro, tendo como referência específica o paulista, parece almejar manter-se em uma posição de observador em frente a um campo em que a cidadania e a justiça são invocadas como meros suportes de sustentação ideológica em contextos nos quais talvez sua invocação não possuísse o devido sentido. ${ }^{26}$

Em comparação com as posições expostas, analisar-se-á o conteúdo dos questionários que foram preenchidos e falas proferidas por pessoas condenadas por crimes de trânsito, as quais cumpriam horas de participação no programa "Reflexão", organizado pela equipe psicopedagógica do Instituto Paz no Trânsito (IPTRAN) em Curitiba. Essas pessoas ${ }^{27}$ foram convidadas a responder a perguntas abertas de extrema densidade conceitual, como: "No que consistiria a cidadania?" "Como ela é exercida no cotidiano?" "Se o questionado teve oportunidade de se expressar e expor suas opiniões sobre ocorrido durante a tramitação do processo penal" etc.

É interessante notar como as respostas foram um tanto heterogêneas na descrição específica da cidadania, mas a maioria a descreveu basicamente como conjunto de deveres e direitos. O ponto em comum de todas as respostas foi que nenhum dos questionados teve a oportunidade de se expressar adequadamente durante a tramitação do processo penal.

Nenhum dos indivíduos se recusou a preencher o questionário, mesmo cientes de que poderiam fazê-lo, porém foram orientados que o tempo de preenchimento seria contabilizado nas horas que estes deveriam cumprir participando dos eventos do Instituto, o que por certo 
evidenciou a adesão e a cooperação. $O$ projeto foi explicado a todos, houve participação nos encontros semanais com os questionados na sede do IPTRAN e a oportunidade de discutir sobre justiça e a proposta do novo paradigma com alguns destes, porém a maioria mostrou-se simpática à iniciativa, mas descrente em sua potencialidade para tratar de crimes mais graves.

Observou-se que, de todos os questionados, apenas um cometeu um crime que resultou vítima (lesão corporal), dois dirigiram alcoolizados, um conduziu veículo com capacidade psicomotora alterada e dois causaram danos materiais a terceiros, mas responderam pelo crime de conduzir sem habilitação, e desses dois, apenas um feriu outrem. Essa foi uma limitação da amostra de pesquisa, pois a existência do dano é um elemento importante para a abertura de espaços, de diálogo e comunicação.

Inicialmente, um dos entrevistados demonstrou encarar a cidadania como o cumprimento de um ônus que implicaria o convívio social harmonioso ("respeitar o espaço e ponto de vista de cada um" [...] "obedecer a regras [...]"). Em seguida, a explicação foi mais complexa, oferecida pela questionada mais jovem, uma estudante universitária: "exercer direitos e deveres para o benefício da população", ou seja, aproximou-se de uma definição que resultaria na responsabilidade do indivíduo com o meio social, ainda que a cidadania afete diretamente a esfera individual. No questionário 3, novamente a cidadania foi tratada como um ônus de respeito ao próximo e de tolerância. No questionário de $\mathrm{n}^{\circ} 5$, foi escrita a frase "pagar as contas". No $\mathrm{n}^{\circ} 4$, o indivíduo explicou o conceito em uma perspectiva mais garantista, embora paradoxalmente tenha descrito a responsabilização personalíssima como "direito de responder pelos meus atos", ou seja, provavelmente o questionado tentou descrever o direito de liberdade de expressão ou do contraditório num contexto de ônus e cobrança de responsabilidade. A resposta presente no questionário 5 também apresentou componentes muito abstratos: "ser uma pessoa que faz as coisas de forma certa, frequenta bons lugares e que exerce a boa moral”. No questionário 6, foi exposta a clássica ideia do limite da liberdade, a qual para o questionado parece se confundir com a cidadania: "respeitar ao próximo e exercer os próprios deveres para poder iniciar seus direitos”.

No caso em que houve vítima, a ofensora buscou entrar em contato com o ofendido e sua família, mas não obteve sucesso. Ela relatou o fato de sentir que a vítima tentou tirar proveito da situação no decorrer do processo (a fim de obter uma indenização maior) e fez constar que as consequências do fato delituoso para a sua vida não receberam atenção, além de que as leis poderiam ser incoerentes, de modo que considerou sua pena desproporcional. A partir de sua percepção, abre-se a questão sobre como o papel de vítima também é socialmente construído, sendo subjetivamente percebido de forma diferenciada por cada sujeito. Dois dos questionados afirmaram, ainda, que o desinteresse do Poder Judiciário pela sua situação e a ausência de chance de se expressar durante o processo configuraram uma "falta de respeito", outros dois simplesmente afirmaram que estavam "errados por descumprir a lei” e que não lhes fez falta não emitirem suas opiniões. 
Com relação à pena aplicada, nos questionários 3 e 4, os indivíduos afirmaram que esta foi justa, porém, no questionário 3, a justificativa foi de que a justiça residiria na previsão legal para sua aplicação. Frisou-se, contudo, que a pena só teria capacidade de transformar positivamente a realidade das pessoas quando na forma de serviço comunitário. Outros dois questionados afirmaram que as penas não teriam tal capacidade, ou por serem legitimadas em fatos diversos dos correspondentes com a realidade, ou por colocarem o apenado em um ambiente hostil sem the dar a chance de "aprender" com o que fez.

Constatou-se então, a partir da arquitetura das respostas oferecidas e da análise teórica sobre o tema, que a abertura a formas alternativas de resolução de conflitos em um ambiente punitivista e imediatista deve ser gradual.

\subsection{JUSTIÇA RESTAURATIVA NOS CRIMES CULPOSOS DE TRÂNSITO}

Conforme Tavares, a importância do estudo dos tipos culposos (ou de imprudência) se relaciona ao incremento de diversas atividades de risco que se tornaram parte do cotidiano com a motorização da vida moderna desde o século XIX. ${ }^{28}$ Desse modo, a razão da extensão de incidência do jus puniendi sobre condutas negligentes lesivas, antes em sua maioria juridicamente irrelevantes e concebidos apenas como quase delictum, foi meramente política, caracterizando-se, portanto, como resposta de política penal a essa nova categoria de danos. Tais danos eram causados mediante o exercício de atividades ou com o consumo de produtos de potencial ofensivo inerente dentro do contexto de uma "sociedade de riscos". Observa-se, então, que as citadas atividades e uso dos referidos produtos inevitavelmente lesariam pessoas, mas a "nova fetichização da mercadoria" transferiu a responsabilidade do dano para o consumidor, ou trabalhador, a fim de impedir que a zona do ilícito penal se estendesse a ponto de frear a prosperidade da indústria e o fomento do consumo. ${ }^{29} \mathrm{O}$ poder de definição foi instrumentalizado para a criação desses tipos penais inéditos não com a latente finalidade de proteger bens jurídicos, mas para garantir a estabilização do conjunto normativo em correspondência com a estrutura capitalista industrial que se formava. Alegou-se que os danos seriam inevitáveis e, então, para evitar que sua concretização fosse tamanha a ponto de desincentivar o fomento do consumo, estabeleceram-se regulamentos específicos de deveres de cuidado e sanções para aqueles que, não os observando, lesassem outrem.

Nota-se que o objetivo foi limitar a perpetuação de danos a um número estatisticamente aceitável e atribuir a responsabilidade do dano somente ao indivíduo, deslocando o foco da questão acerca do potencial ofensivo dos produtos e atividades. Frisa-se que o processo de tipificação foi também muito tópico para não tornar demasiadamente temeroso o uso de produtos ou o exercício das referidas atividades por parte dos consumidores e operários.

De acordo com Zaffaroni, o problema do crime culposo não está atrelado à finalidade do agente, mas sim à maneira como este pretende realizar sua ação, a qual, prima facie, é 
atípica. ${ }^{30} \mathrm{~A}$ seleção dos meios para se cumprir o objetivo da conduta, portanto, atém-se a um standard mínimo ${ }^{31}$ formulado a partir de regulamentos e outras orientações normativas com o intuito de minimizar os riscos de causar um dano a outrem. Ressalta-se que, embora o autor reconheça que os conceitos de reasonable man e standard mínimo sejam vagos e imaginários, ele defende a adoção de um standard empiricamente verificável (provavelmente por fatores estatísticos) como referência para a imputação de prática de crime culposo. Nessa senda, caso o agente possua peculiaridades que o impossibilitem de ser avaliado conforme o referido padrão, estas devem ser analisadas no âmbito da culpabilidade (hipótese questionável, por ter cunho universalizante, mas deve-se reconhecer que a solução referente à culpabilidade é tecnicamente aceitável). O autor, então, soma à equação, cujo resultado é a imputação da conduta culposa, o fator "azar", afinal a conduta pode ser praticada em desconformidade com os deveres de cuidado (previstos em outras normas esparsas e, portanto, incorrendo na caracterização do tipo culposo como "aberto"), mas sem a concretização do resultado típico.

Nesses termos, a aplicação da sanção penal remete muito mais a um desvalor de resultado que a um desvalor de ação, incluída nesta a dimensão subjetiva, ausente na forma dolosa. Trata-se da inobservância de um dever de cuidado, da criação de risco não permitido, da elevação de risco permitido, mas trata-se sobretudo de um dano, por vezes, muito significativo, resultante de tal conduta "descuidada" ou "criadora de risco" por parte do agente.

Para esse tipo específico de crime, a pena privativa de liberdade é quantitativamente inferior em comparação a seus correspondentes dolosos e ainda substituível pela pena restritiva de direitos. Essa substituição é prevista no art. 44, inciso I, do Código Penal Brasileiro e evidencia a opção por tratamento penal diferenciado, em termos qualitativos, dos autores de delitos culposos.

Como afirmado, a possível diferenciação penal na tratativa dos crimes culposos se dá pela ausência de dolo do agente em concretizar o tipo objetivo, o que denota o fato de este, aos olhos do legislador, não ser digno de um tratamento tão severo como o direcionado aos autores de crimes dolosos, pois a intenção deste não seria penalmente reprovável. Nota-se, inclusive, que tem-se tornado, infelizmente, comum, na praxis forense, tipificar condutas evidentemente culposas como portadoras de "dolo eventual" porque o resultado é por demais lesivo e significativo, do ponto de vista da opinião pública. Ora, é evidente que o sentido de "justiça" e sua subjetiva percepção pela população não são parâmetros para a métrica quantitativa da pena privativa de liberdade. Tal desvalor de resultado deve ser colocado em pauta e dentro da criação de um espaço de comunicação capaz de explicitar responsabilidades, espaço inexistente e inviabilizado pelo processo penal tradicional.

De todo modo, parece razoável dizer que a sociedade e a comunidade jurídica seriam facilmente receptivas à proposta de adoção de práticas restaurativas nos processos envolvendo casos de delitos culposos. Diante de todos, está o dano, mas não tanto, ou de forma tão intensa, o "agressor", pois o "criminoso" vem ab initio destituído do componente subjetivo 
como objeto de ódio e hostilidade. A desconstrução de estereótipos e a abertura de canais de fala e escuta podem ser facilitadas com tal ponto de partida.

Pragmaticamente, a possibilidade de substituição das penas privativas de liberdade aplicadas a crimes culposos por restritivas de direitos também evidencia a maior facilidade em fazer disso um processo participativo de formulação de medidas de censura visando à compensação, na medida do possível, do dano causado.

Segundo dados divulgados pelo Departamento Nacional de Trânsito (DENATRAN), a frota de veículos brasileira, em junho de 2014, foi estimada em 84.063.191, ${ }^{32}$ e, conforme o Mapa da Violência, ${ }^{33}$ em 2012, 43.821 pedestres foram internados somente pelo SUS (27,5\% do total de internações envolvendo acidentes de trânsito). Em 2011, foram registrados os óbitos de 11.959 pedestres, e, segundo o Ministério da Saúde, no mesmo ano, registraram-se 43.256 mortes no trânsito. Parcela considerável desses acidentes está associada ao alcoolismo e/ou a crimes culposos de trânsito (homicídio e lesão corporal grave), entretanto, desde 1997 até o momento, apenas 8 pessoas cumprem ou cumpriram pena em regime fechado devido à condenação por crime de trânsito, sendo que, desse total, 7 cometeram crimes tidos como dolosos e 1 por tentativa de homicídio. Portanto, sendo que os delitos culposos mais graves, como homicídios e lesões corporais, estão associados ao trânsito ou a casos não frequentes de adultos que esquecem crianças dentro de veículos (nesses, a repercussão midiática é maior), atesta-se que o efetivo encarceramento de autores de crimes culposos já não ocorre (mesmo, por exemplo, em casos de homicídio culposo com pluralidade de vítimas).

A tratativa especial passível de aplicação às penas dos delitos culposos, nos termos já explicitados, torna o ambiente do conflito, causado por esse tipo de crime, propício à instauração de medidas restaurativas, na medida em que essas são calcadas nos pilares da pessoalidade, reparação, reintegração e participação, ${ }^{34}$ absolutamente coerentes aos anseios do legislador diante da substituição da pena da reclusão por práticas de reparação ou compensação.

Fundamental compreender, no entanto, que a mera aplicação de penas restritivas de direito não implica, por si só, a caracterização de tais medidas como "restaurativas". De acordo com o exposto e a perspectiva minimalista, a adjetivação do processo como restaurativo depende da forma pela qual se chegou a essa medida, do "processo", da participação ativa, respeitosa, voluntária e empoderada dos sujeitos vitimizados e criminalizados e suas comunidades de suporte. Essa é também a posição das Nações Unidas (Resolução 2002/12ONU): restaurativo deve ser o processo, não o resultado. ${ }^{35}$

Ainda, inexistiria o fator "medo" como óbice ao encontro e diálogo entre ofensor e ofendido, de forma que o desejo da vítima ou de sua família de se aproximar do infrator seria maior. Afinal, esses almejariam sua responsabilização e retratação, ou ao menos "compreender o que aconteceu". Nos processos que envolvem crimes dolosos, tal encontro é possível, porém evidentemente mais complicado, pois é comum que se construa, com o 
incentivo da própria legislação e dos operadores do sistema de justiça, verdadeiro pavor da vítima em relação a seu agressor. Howard Zehr trata dessa questão afirmando que a citada aversão se desenvolve devido à posição submissa na qual a vítima é colocada por seu ofensor, sendo o seu posterior empoderamento, proporcionado pelo protagonismo processual no decorrer do rito de resolução conflitual, a forma mais adequada de desconstituí-la. ${ }^{36}$ Esse trauma pode ser sentido pelos efeitos do delito culposo como em casos nos quais o agente esquece o bebê trancado no carro, provoca um incêndio sem intenção (fogos de artifício, fogão ligado, etc.), provoca lesões ou mesmo a morte de pessoas passageiras do veículo que conduz, etc. Entretanto, a intenção do agente não foi um dos fatores que deu causa ao trauma, de modo que a vítima e os seus familiares não considerariam sua conduta como algo arquitetado cruelmente e, mais além, não teriam razão para temê-lo. Os referidos fatores podem não inibir a raiva que recairá sobre o responsável, mas eles contribuem para o êxito em uma tentativa de aproximação.

O foco da justiça restaurativa pode não ser o perdão ou a restauração absoluta do status pré-delito, porém essa cria um ambiente propício à concretização de uma relação de comunicação imprescindível à própria censura e à responsabilização, muito mais, e muito além de apenas humanizar, informalizar ou "esvaziar prateleiras". Seria então possível vivenciar, por meio do diálogo e do conhecimento mútuo, uma autêntica experiência de alteridade. Em relação a esse otimismo, entretanto, Declan Roche, em Accountabily in Restorative Justice, fez a ressalva de que, enquanto as partes podem expor a "melhor face da natureza humana", demonstrando empatia, buscando compreensão mútua e reconciliando-se, existe também a chance dos ciclos restaurativos apenas servirem como mais um espaço de humilhação e demonização, principalmente em relação ao censurado. Para evitar tal problema, faz-se mister a participação de facilitadores capacitados e, se necessário, deve-se observar que, por ser baseado no princípio da voluntariedade, qualquer um dos envolvidos pode desistir do rito restaurativo.

Mesmo com a ressalva, Roche afirma que o fato de o apenado ter participado na formulação de sua sentença implica uma assunção de comprometimento muito maior do que se esta fosse meramente imposta pela corte, o que está intimamente ligado com a questão da justiça restaurativa ser muito mais personalista do que a justiça convencional. ${ }^{37} \mathrm{~A}$ referida assunção de comprometimento, para o estudo em questão, é um fator de extrema relevância, pois o cumprimento de uma pena restritiva de direitos depende muito da pró-atividade do apenado em comparecer ao local de sua execução, por exemplo.

A tratativa legal e midiática desse tipo de crime permite inferir que a comunidade jurídica seria mais suscetível a aceitar a intervenção de outras metodologias processuais nesta esfera institucional específica. Boaventura de Sousa Santos defende que o direito estatal não pode ser encarado como o único legítimo diante da diversidade de culturas jurídicas existentes e da forma como estas também se apresentam como eficientes em 
oferecer soluções para conflitos. ${ }^{38}$ Roberto Lyra Filho, por sua vez, define que o direito autêntico é aquele que visa à justiça social atentando às peculiaridades de seus destinatários e das minorias sociais de forma solidária. ${ }^{39}$ Nesses termos, entende-se que a justiça restaurativa se apresenta como uma autêntica e humanitária abordagem de se operar o direito penal em conformidade com a Constituição e com os direitos humanos. Ainda que o resultado final do processo não se altere, é inegável que os meios para atingi-lo garantiriam mais respeito à autonomia e à dignidade da pessoa humana, sendo a tratativa dos delitos culposos o canal ideal para se iniciar a disseminação de tal paradigma para além dos casos envolvendo adolescentes em conflito com a lei. Hoje, o principal foco da aplicação dos métodos restaurativos no país, e a resolução 125/2010 do CNJ evidencia isso, ainda são os casos envolvendo os referidos adolescentes, sendo que a condução de tais casos é influenciada em grande parte por pastorais e ONGs regionais.

Em relação às finalidades da justiça restaurativa, não se trata de pretender a ressocialização ou incutir aflição ao apenado. Ambos os citados objetivos afrontam a dignidade da pessoa humana, seja por desrespeitar a esfera subjetiva do apenado, tornando-o um objeto de intervenção situado em uma relação vertical de poder, seja pela crueldade inerente a qualquer censura que almeje a produção de dor e sofrimento. Algo próximo ao retributivismo, em sua vertente comunicativa, relaciona-se de melhor forma com as finalidades da justiça restaurativa. ${ }^{40}$

Juristas antipáticos ao modelo restaurativo acusam-no injustamente de se apresentar como uma alternativa soft punishment para o ofensor, de modo que esse se prontificaria rapidamente em participar dos ciclos restaurativos apenas com intenção de minimizar os efeitos da pena. Tratando-se dos crimes culposos, como se constatou, a possibilidade de o ofensor sentir um remorso genuíno pela violação do dever de cuidado é considerável, porém, supondo que o referido "fingimento" de fato ocorra, deve-se discordar que a justiça restaurativa se configura como uma maneira mais branda de responsabilização. Estar diante daquele(s) que lesou, retratando-se e ouvindo, constitui experiência psicologicamente desconfortável, pois ele conhecerá minuciosamente as dimensões e os detalhes dos danos que veio a causar. Soft, portanto, não parece ser uma designação justa à abordagem restaurativa.

Os ciclos restaurativos fornecem uma chance de diálogo inexistente no processo judicial convencional. Essa mesma ânsia de assumir a responsabilidade e de responsabilizar, mais facilmente presente nos casos de delitos culposos, reduz as chances de desistência da adoção da linha restaurativa de resolução conflitual ao longo dos encontros realizados. O fato de o ofensor não ter almejado lesar o ofendido, nesses casos, amplia as possibilidades de construção conjunta de medidas de reparação simbólica, permitindo que ambos os lados possam prosseguir suas trajetórias de vida de maneira menos penosa ou traumática. 
Fato é que a imposição de uma sentença, a qual, por vezes, prevê uma compensação totalmente desconexa com o dano resultante do delito, somada a uma responsabilização padronizada realizada por um juiz e membros do Ministério Público, e não pela própria vítima ou sua família (que tiveram uma relação mais estreita com o fato delituoso), não contribui para a construção de percepções de justiça e responsabilidade.

\section{CONCLUSÃO}

A perspectiva adotada, nesses termos, corresponde à encounteer theory ou à vertente minimalista, restando o foco mais sobre o processo que sobre o resultado. Tem-se, por certo, que os objetivos principais da perspectiva restaurativa seriam, portanto: i) a reconstrução de vínculos intersubjetivos rompidos pela ofensa; ii) o tratamento e a reflexão sobre o trauma causado pelo ato delituoso; iii) a responsabilização do ofensor com fundamento na alteridade e na rejeição das novas formas de "ortopedia moral"; iv) a promoção e a reflexão sobre as causas e as possíveis soluções para o conflito em sentido mais amplo. Todos esses pontos, entretanto, dependem do diálogo (direto ou indireto) entre ofendido e ofensor, de modo que esse deve ser considerado como fator indispensável à metodologia adotada, enquanto a reparação adquiria natureza fortemente simbólica, como consequência, ou não, do cumprimento do acordo restaurativo.

Há de se ter cuidado com as categorias prontas como "vítima e ofensor", as quais, como apontou Cunneen, são heterogêneas. Inexiste, desse modo, uma fórmula padrão para conduzir um diálogo entre os envolvidos no conflito. $\mathrm{O}$ autor afirmou contundentemente que a justiça restaurativa, por vezes, tenta encapsular figuras complexas em conceitos gerais, estigmatizantes e abstratos; logo, caberia observar que, embora venha a existir um protocolo para a organização do rito restaurativo, esse deve calcar-se também no princípio da criatividade, uma vez que a abordagem restaurativa é essencialmente casuística, caso contrário poderia ser infectada pela lógica processual convencional. ${ }^{41}$

A vertente sociopolítica, da qual a justiça restaurativa se aproxima, é definida como "comunitarismo", descrita por Reggio ${ }^{42}$ como uma forma de regimento social no qual grande parte do poder decisório se encontraria nas mãos da comunidade, que exprimiria uma maior preocupação social com o corpo coletivo. Tal vertente apoia-se na participação ativa e democrática. Os valores sociais seriam refletidos na atuação das instituições sociais, mas a sociedade depositaria na figura da comunidade a fé para a resolução dos conflitos, a qual seria realizada de maneira mais informal mas em conformidade com os referidos valores. Transcender-se-iria o individualismo, configurando-se um grupo de pessoas que salvaguardariam a ordem social de forma não autoritária, mas responsável, a partir da construção de um projeto cultural e político, o qual implicaria a democratização de uma sensação de pertencimento partilhada entre os componentes sociais. ${ }^{43}$ 
Sendo um modelo paradigmático de resolução conflitual inclusivo, capaz de reparar e criar laços intersubjetivos entre pessoas fomentando o uso da racionalidade e do senso de responsabilidade para com o outro e o coletivo, além de operar como um instrumento para a identificação dos problemas sociais que contribuem para a ocorrência de conflitos mais graves, a justiça restaurativa se apresenta como apta a redefinir a cidadania brasileira. A adoção de tal perspectiva, a longo prazo, poderia implicar a superação de uma cidadania formal rumo a uma substancial (na linha de Holston) e, em um segundo estágio, para o que se define aqui como a "autêntica cidadania." Esse conceito seria, portanto, o status social reconhecido a um indivíduo pela sociedade com a qual este possui um vínculo intersubjetivo potencialmente perene, de modo que tal condição implique a conferência de uma série de deveres de responsabilidade para com a coletividade e os problemas sociais que a afetam e no complementar reconhecimento e efetivação de direitos que permitam a autorrealização e a expressão da subjetividade individual.

A seara dos crimes culposos, por fim, parece indicar um caminho seguro e legítimo para projetos piloto e experiências inovadoras ainda não adotados com tanta intensidade no Brasil. Possibilitando que os envolvidos no conflito vivenciem uma experiência democrática e atuem como protagonistas, capazes e responsáveis, sem a dependência de especialistas, as práticas restaurativas abrem um canal emancipador e inspirador que não se confunde com a banalização da violência promovida pelo seu uso, de modo injusto e desmedido, por parte do próprio Estado.

\section{REFERÊNCIAS}

BRASIL. Departamento Nacional de Trânsito. Frota Nacional (Junho de 2014). 2014. Disponível em: <http://www.denatran.gov.br/frota2014.htm>. Acesso em: 6 ago. 2014.

CALDEIRA, Teresa. Violência, direitos e cidadania: relações paradoxais. Ciência e Cultura, São Paulo, v. 54, n. 1, p. 44-46, 2002. Disponível em: <http://cienciae cultura.bvs. br/scielo.php?pid $=$ S0009-67252002000100021\&script $=$ sci_arttext\&tlng $=e m>$. Acesso em: 19 jan. 2015.

CARVALHO, Luiza Maria S. dos Santos. Notas sobre a promoção da equidade no acesso e intervenção da Justiça Brasileira. In: SLAKMON, Catherine; DE VITTO, Renato Campos Pinto; PINTO, Renato Sócrates Gomes (Org.) . Justiça Restaurativa. Brasília: PNUD, 2005. p. 211-224.

CHRISTIE, Nils. Conflict as Property. The British Journal of Criminology, Oslo, v. 17, n. 1, p. 1-15, 1977. 
CLARK, William A. V. Geography in Court: Expertise in Adversarial Settings. Transactions of the Institute of British Geographers, Londres, v. 16, n. 1, p. 5-20, 1991.

CUNNEEEN, Chris; HOYLE, Carolyn. Debating Restorative Justice. Portland Oregon: Hart Publishing, 2010.

DE VITTO; Catherine; OXHORN, Philip. Micro-justiça, desigualdade e cidadania: a construção da sociedade civil através da Justiça Restaurativa no Brasil. In: SLAKMON, Catherine; DE VITTO, Renato Campos Pinto; PINTO, Renato Sócrates Gomes (Org.). Justiça Restaurativa. Brasília: PNUD, 2005. p. 187-210.

FEELEY, Malcom M. The Process is the Punishment: Handling Cases in a Lower Criminal Court. Nova Iorque: Russel Sage Foundation, 1992.

GIAMBERARDINO, André. Crítica da pena e justiça restaurativa: a censura para além da punição. Florianópolis: Empório do Direito, 2015.

HOLSTON, James. Insurgent Citizenship: Disjunction of Democracy and Modernity in Brazil. Princeton: Princeton University Press, 2008.

LYRA FILHO, Roberto. Razões de defesa do direito. Brasília: Editora Obreira, 1981.

ORGANIZAÇÃO DAS NAÇÕES UNIDAS. Resolução 2002/12: princípios básicos para utilização de Justiça Restaurativa em matéria criminal. Nova Iorque: Conselho Econômico e Social da ONU, 2002.

REGGIO, Federico. Giustizia dialogica: luci e ombre della restorative justice. Milão: Editora Franco Angeli, 2010.

ROCHE, Declan. Accountabily in Restorative Justice. Oxford: Oxford University Press, 2003.

SANTOS, Boaventura de Sousa. O discurso e o poder. Porto Alegre: Editora Sérgio Fabris, 1988.

TAVARES, Juarez. Teoria do crime culposo. 3. ed. Rio de Janeiro: Lúmen Júris, 2009.

WAISELFISZ, Julio Jacobo. Mapa da violência 2013: acidentes de trânsito e motocicletas. Rio de Janeiro: Centro Brasileiro de Estudos Latino-Americanos, 2013.

ZAFFARONI, E. Raúl; BATISTA, Nilo. Direito Penal Brasileiro: introdução histórica e metodológica, ação e tipicidade. 2. ed. Rio de Janeiro: Revan, 2010. v. 2.

ZAFFARONI, E. Raúl; PIERANGELI, José Henrique. Manual de Direito Penal Brasileiro: parte geral. 6. ed. São Paulo: Revista dos Tribunais, 2006. v. 1.

ZERH, Howard. Trocando as lentes: um novo foco sobre o crime e a justiça. São Paulo: Palas Athena, 2008. 
1 A análise focou-se na compreensão: i) das implicâncias jurídicas da ocorrência de delitos de trânsito, ii) da tratativa do Judiciário em relação a tais casos, iii) da identificação de casos propícios ao êxito da adoção de práticas restaurativas. A consulta processual foi semanal, e se deu com a autorização do juiz responsável pela respectiva vara. Entre os autos em questão, estão aqueles nos quais ocorreram condenação ou absolvição do réu, pois ainda não existia uma estratégia de acompanhamento e implementação da metodologia restaurativa para os processos ainda em tramitação.

2 Tal contato foi baseado i) no acompanhamento das reuniões de grupo e atividades com os ofensores e as famílias dos ofendidos (os quais sofreram óbito por acidente de trânsito); ii) na apresentação do projeto aos infratores e às famílias e iii) na aplicação de questionários aos ofensores, os quais tratariam de suas concepções acerca de justiça, cidadania e ofereceriam as suas opiniões sobre a pena que cumpriam e acerca da condução do processo no qual foram réus.

3 CLARK, William A. V. Geography in court: expertise in adversarial settings. Transactions of the Institute of British Geographers, Londes, v. 6, n. 1, p. 14, 1991.

4 FEELEY, Malcom M. The Process is the punishment: handling cases in a lower criminal court. Nova Iorque: Russel Sage Foundation, 1992. p. 27.

5 REGGIO, Federico. Giustizia dialogica: luci e ombre della restorative justice. Milão: Editora Franco Angeli, 2010. p. 21-24.

6 Ibid, p. 61.

7 Ibid, p. 69-72.

8 Ibid, p. 79-81.

9 CHRISTIE, Nils. Conflict as property. The British Journal of Criminology, Oslo, v. 17, n. 1, p. 3, 1977.

10 Ibid, p. 8-9.

11 ZERH, Howard. Trocando as lentes: um novo foco sobre o crime e a justiça. São Paulo: Palas Athena, 2008. p. 199-202.

12 Ibid, p. 185-186.

13 CUNNEEEN, Chris; HOYLE, Carolyn. Debating restorative justice. Portland Oregon: Hart Publishing, 2010. p. 2.

14 ZEHR, op. cit., p. 89-90.

15 REGGIO, op. cit., p. 66-67.

16 REGGIO, op. cit., p. 163. Mark Umbreit crítica a mediação que foca em uma composição material, para ele, é mais relevante o encontro entre vítima e ofensor, "mediação humanitária", baseado no reconhecimento do alter e de uma humanidade mútua, o que só seria possível com um encontro face a face. Por meio desse reconhecimento, as partes se tornariam mais abertas ao diálogo, mais responsáveis e mais dispostas a compreender o ponto de vista uma da outra. $\mathrm{O}$ acordo restaurativo então possuiria uma importância secundária na perspectiva da Encounter Theory (REGGIO, op. cit., p. 101-102).

17 CUNNEEEN; HOYLE, op. cit., p. 42-47,

18 CUNNEEEN; HOYLE, op. cit., p. 125.

19 DE VITTO; Catherine; OXHORN, Philip. Micro-justiça, desigualdade e cidadania: a construção da sociedade civil através da Justiça Restaurativa no Brasil. In: SLAKMON, Catherine; DE VITTO, Renato Campos Pinto; PINTO, Renato Sócrates Gomes (Org.). Justiça Restaurativa. Brasília: PNUD, 2005. p. 190.

20 DE VITTO; OXHORN, op. cit., p. 199.

21 CARVALHO, Luiza Maria S. dos Santos. Notas sobre a promoção da equidade no acesso e intervenção da Justiça Brasileira. In: SLAKMON, Catherine; DE VITTO, Renato Campos Pinto; PINTO, Renato Sócrates Gomes (Org.). Justiça Restaurativa. Brasília: PNUD, 2005. p. 215.

22 HOLSTON, James. Insurgent citizenship: disjunction of democracy and modernity in Brazil. Princeton: Princeton University Press, 2008. p. 3, 28-30, 63-64.

23 HOLSTON, op. cit., p. 190.

24 SANTOS, Boaventura de Sousa. O discurso e o poder. Porto Alegre: Editora Sérgio Fabris, 1988. p. 139.

25 SANTOS, op. cit., p. 141.

26 CALDEIRA, Teresa. Violência, direitos e cidadania: relações paradoxais. Ciência e Cultura, São Paulo, v. 54, n. 1, p. 44-46, 2002. Disponível em: <http://cienciae cultura.bvs.br/scielo.php?pid=S0009$-67252002000100021 \&$ script $=$ sci_arttext\&tlng $=$ em $>$. Acesso em: 19 jan. 2015. 
27 Dois terços (2/3) dos questionados não possuíam ensino superior. A idade mínima foi de 25 anos e a máxima 61 (considerando apenas aqueles que a identificaram). Cinco sextos (5/6) dos questionados foram condenados por cometerem crimes muito leves e de perigo abstrato.

28 TAVARES, Juarez. Teoria do crime culposo. 3. ed. Rio de Janeiro: Lúmen Júris, 2009. p. 10.

29 TAVARES, op. cit., p. 11.

30 ZAFFARONI, E. Raúl; PIERANGELI, José Henrique. Manual de Direito Penal Brasileiro: parte geral. 6. ed. São Paulo: Revista dos Tribunais, 2006. v. 1. p. 435-441.

31 ZAFFARONI, E. Raúl; BATISTA, Nilo. Direito Penal Brasileiro: introdução histórica e metodológica, ação e tipicidade. 2. ed. Rio de Janeiro: Revan, 2010. v. 2. p. 327-330.

32 BRASIL. Departamento Nacional de Trânsito. Frota Nacional (Junho de 2014). 2014. Disponível em: <http://www.denatran.gov.br/frota2014.htm>. Acesso em: 6 ago. 2014.

33 WAISELFISZ, Julio Jacobo. Mapa da violência 2013: acidentes de trânsito e motocicletas. Rio de Janeiro: Centro Brasileiro de Estudos Latino-Americanos, 2013. p. 62-74.

34 ROCHE, Declan. Accountabily in restorative justice. Oxford: Oxford University Press, 2003 p. 8.

35 ORGANIZAÇÃO DAS NAÇÕES UNIDAS. Resolução 2002/12: princípios básicos para utilização de Justiça Restaurativa em matéria criminal. Nova Iorque: Conselho Econômico e Social da ONU, 2002.

36 ZEHR, op. cit., p. 205.

37 ROCHE, op. cit., p. 4-5.

38 SANTOS, op. cit., p. 9-17.

39 LYRA FILHO, Roberto. Razões de defesa do direito. Brasília: Editora Obreira, 1981. p. 12.

40 GIAMBERARDINO, André. Crítica da pena e justiça restaurativa: a censura para além da punição. Florianópolis: Empório do Direito, 2015.

41 CUNNEEEN; HOYLE, op. cit., p. 132-134.

42 REGGIO, op. cit., p. 35.

43 CUNNEEEN; HOYLE, op. cit., p. 93.

\title{
RESTORATIVE JUSTICE AND UNINTENTIONAL TRAFFIC OFFENCES
}

\begin{abstract}
The restorative paradigm is proposed as a way to empower and emancipate citizens from a state of apathy and passiveness with regard to their relationship to conflict and its resolution. Focusing specifically on unintentional traffic crimes, the research was organized in two phases, combining a qualitative methodology based on unstructured interviews and observation with qualified literature review. As such, the research was carried out in the Second Court of Traffic Offences of Curitiba, Paraná, and through the interaction, at the "Paz no Trânsito" Institute, with family members of victims of traffic offences, as well as offenders who were serving a sentence. As the restorative rite is a volunteer experience that encourages dialogue, reflection about the causes of the issue and the joint formulation of a solution to the
\end{abstract}


conflict, it may demonstrate that the person is able to act responsibly and act as a modifying agent of their own reality. It follows that the field of culpable and transit crimes appears as fertile ground to test the effectiveness of this form of justice, due to the absence of direct purpose in causing the damage and the ineffectiveness of State punishment in preventing the offence.

Keywords: Restorative Justice. Unintentional crimes. Citizenship.

Submetido: 21 mar. 2017

Aprovado: 28 abr. 2017 